\title{
PENGARUH MODEL QUANTUM TEACHING TERHADAP HASIL BELAJAR SISWA PADA PEMEBELAJARAN TEMATIK KELAS V DI SEKOLAH DASAR
}

\author{
Raya Sigalingging, Darinda Sofia Tanjung, Rumiris Lumban Gaol \\ Surel: sigalinggingraya@gmail.com
}

\begin{abstract}
This study is a quantitative study that aims to determine the effect of the Quantum Teaching learning model on student learning outcomes conducted at SD Negeri 106144 Sei Mencharim 2020/2021. This research method is descriptive method. The population of this study were all fifth grade students of SD Negeri 106144 Sei Menistrim which consisted of one class with a total of 30 students. The results showed that the Quantum Teaching model was included in the good category with an average of 80.7, the correlation coefficient was 0.705, which means that r_count (0.705) r_table (0.361), then $h$ _a is accepted. Hypothesis testing shows that tcount > ttable is 6.363 1.697, thus stating that h_a is accepted. It can be concluded that the Quantum Teaching learning model has an influence on learning outcomes
\end{abstract}

Keywords: Learning Outcomes, Thematic, Quantum Teaching Model

\begin{abstract}
ABSTRAK
Penelitian ini merupakan penelitian kuantitatif yang bertujuan mengetahui pengaruh model pembelajaran Quantum Teaching terhadap hasil belajar siswa yang dilakukan di SD Negeri 106144 Sei Mencirim 2020/2021. Metode yang digunakan adalah metode deskriptif. Populasi penelitian ini seluruh siswa kelas V SD Negeri 106144 Sei Mencirim yang terdiri dari satu kelas dengan jumlah 30 siswa. Hasil penelitian menunjukkan model Quantum Teaching termasuk kategori baik dengan rata-rata 80,7, hasil koefisien kolerasi sebesar 0,705 artinya $r_{\text {hitung }}(0,705) \geq r_{\text {tabel }}$ $(0,361)$ maka $h_{a}$ diterima. Pengujian hipotesis menunjukkan $t_{\text {hitung }}>\mathrm{t}_{\text {tabel }}$ yaitu $6,363 \geq 1,697$ sehingga menyatakan bahwa $h_{a}$ diterima. Dapat disimpulkan model pembelajaran Quantum Teaching memiliki pengaruh terhadap hasil belajar.
\end{abstract}

Kata Kunci: Hasil Belajar, Tematik, Model Quantum Teaching

\section{PENDAHULUAN}

Pendidikan merupakah suatu proses yang dilalui seseorang melalui pengajaran, pelatihan dan penelitian dengan berbagai macam metode, pendekatan, stategi bahkan model pembelajaran untuk mengembangkan pengetahuan, mengembangkan potensi yang dimiliki seseorang dan menumbuhkan sikap yang baik dalam 
bertingkah laku di dalam masyarakat dan bernegara. Pendidikan juga mampu membuat seseorang untuk mendalami apa yang diketahui, sebab itu pendidikan mampu mendewasakan seseorang dan tidak dapat terlepas dari kehidupan manusia sampai kapanpun.

Pendidikan tidak pernah luput dari proses pembelajaran yang meliputi seluruh aktifitas yang menyangkut pemberian materi pelajaran guna siswa memperoleh pengetahuan. Proses pembelajaran akan bermakna jika interaksi antara guru dan siswa optimal, dimana peserta didik berperan aktif dalam proses pembelajaran yang berlangsung. Namun pada kenyataannya kegiatan belajar mengajar masih ada yang menempatkan guru sebagai penyampaian materi pembelajaraan dengan metode ceramah siswa hanya diam dan mendengarkan ceramah guru. Proses pembelajaraan tersebut dianggap kurang efektif sebagai metode untuk menjalankan fungsi dan tujuan pendidikan.

Untuk memperbaiki hasil belajar siswa harus memotivasi siswa untuk lebih aktif dalam proses pembelajaran agar mendapatkan hasil belajar yang baik. Banyak model pembelajaran yang dapat digunakan dalam proses pembelajaran, akan tetapi penelitian menggunakan model pembelajaran Quantum Teaching untuk meningkatkan hasil belajar siswa dan lebih meningkatkan siswa untuk lebih aktif.

Berdasarkan pengamatan peneliti di SD Negeri 106144 Sei
Mencirim bahwa proses pembelajaran masih pada guru sebagai pemberi informasi sedangkan siswa cenderung pasif dan hanya menerima pembelajaran. Selama proses pembelajaran guru menulis dipapan tulis lalu siswa mencatat dibuku catatannya setelah itu guru menerangkan pembelajaran dan mengerjakan soal dibuku lembar kerja siswa. Proses pembelajaran yang dilakukan menjadi kurang bermakna dan berpengaruh pada hasil belajar siswa. Hal ini disebabkan oleh siswa yang belum paham akan materi yang dijelaskan oleh guru pada saat kegiatan belajar mengajar berlangsung.

Quantum Teaching adalah Badan ilmu pengetahuan dan metodologi yang digunakan dalam rancangan, pengajian dan fasilitas. Quantum Teaching juga menyertakan segala kaitan, interaksi, dan perbedaan yang memaksimalkan momen belajar. Quantung Teaching berfokus pada hubungan dinamis dalam lingkungan kelas interaksi yang mendirikan landasan dan kerangka untuk belajar. Quantum teaching merangkaikan yang paling baik dari yang terbaik menjadi sebuah paket multisensori, multikecerdasan, dan kompatibel dengan otak, yang pada akhirnya akan melejitkan kemampuan guru dan kemampuan murid untuk berprestasi.

Soekamto (Nurulwati, 2000:

10) mengemukakan maksud dari model pembelajaran adalah kerangka konseptual yang melukiskan prosedur yang sistematis dalam mengorganisasikan pengalaman 
belajar untuk mencapai tujuan belajar tertentu, dan berfungsi sebagai pedoman bagi para perancang pembelajaran dalam merencanakan aktivitas belajar mengajar. Hal ini berarti model pembelajaran memberikan kerangka dan arah bagi guru untuk mengajar.

\section{METODE PENELITIAN}

Penelitian ini dilaksanakan pada siswa kelas V SD Negeri 106144 Sei Mencirim Tahun Pembelajaran 2020/2021. Tempat penelitian ini beralamat di Jl. Pasar 1 Sei Mencirim, Kec. Sunggal, Kab. Deli Serdang, Sumatera Utara. Dalam melakukan sebuah penelitian, peneliti harus menetukan pendekatan penelitian karena pendekatan berperan penting dalam melakukan sebuah penelitian. Pendekatan yang digunakan dalam penelitian ini adalah pendekatan kuantitatif. Menurut Sugiyono (2018: 14) Penelitian kuantitatif dapat diartikan sebagai, "Metode penelitian yang berlandaskan positivisme, digunakan untuk meneliti pada populasi atau sampel tertentu, teknik pengambilan sampel pada umumnya dilakukan secara random, pengumpulan data menggunakan instrumen penelitian, analisis data bersifat kuantitatif/Statistik dengan tujuan untuk menguji hipotesis yang telah ditetapkan".

Dalam penelitian tidak terlepas dari metode penelitian karena dari metode penelitian dapat diketahui apa tujuan peneliti. Menurut Sugiyono (2018: 13) "Metode penelitian adalah cara ilmiah untuk mendapatkan data dengan tujuan dan kegunaan tertentu". Metode penelitian yang penulis gunakan dalam penelitian ini yaitu metode deskriptik analitik dengan tujuan untuk menganalisis data sampel dan hasilnya diberlakukan untuk populasi.

\section{HASIL PENELITIAN DAN PEMBAHASAN}

Hasil Pre Test yang telah dilaksanakan menunjukkan bahwa kemampuan hasil belajar siswa dikatakan cukup.

Tabel 1. Distribusi Trekuensi Nilai Pre Test Kelas V

\begin{tabular}{c|c|c|c}
\hline No & Nilai & Frekuensi & Presentase \\
\hline 1 & $30-35$ & 3 & $9,99 \%$ \\
\hline 2 & $36-41$ & 2 & $6.66 \%$ \\
\hline 3 & $42-47$ & 6 & $19.99 \%$ \\
\hline 4 & $48-53$ & 2 & $6.66 \%$ \\
\hline 5 & $54-59$ & 3 & $9.99 \%$ \\
\hline 6 & $60-65$ & 4 & $13.33 \%$ \\
\hline 7 & $66-71$ & 1 & $3.33 \%$ \\
\hline 8 & $72-77$ & 4 & $13.33 \%$ \\
\hline 9 & $78-83$ & 3 & $9.99 \%$ \\
\hline 10 & $84-89$ & 2 & $6.66 \%$ \\
\hline \multicolumn{2}{|c|}{ Jumlah } & 30 & $100 \%$ \\
\hline \multicolumn{4}{l}{}
\end{tabular}

Berdasarkan data di atas dapat diketahui nilai Pre Test siswa yaitu: 3 responden memperoleh skor disekitar 30-35 sebesar 9,99\%, 2 responden memperoleh skor disekitar 36-41 sebesar $6,66 \%, 6$ responden memperoleh skor sekitar 42-47 sebesar 19.99\%, 2 responden memperoleh skor sekitar $6.66 \%, 3$ responden memperoleh skor sekitar 9.99\%, 4 responden memperoleh skor sekirar $13.33 \%, 1$ responden memperoleh skor sekitar 3.33\%, 4 responden memperoleh skor sekitar $13.33 \%$, 3 responden memperoleh skor sekitar 9.99\%, 2 responden memperoleh skor sekitar $6.66 \%$. 
Raya Sigalingging, Darinda Sofia Tanjung, Rumiris Lumban Gaol : Pengaruh Model ....

Tabel 2. Distribusi Trekuensi Nilai Post Test kelas V

\begin{tabular}{c|c|c|c}
\hline No & Nilai & Frekuensi & Presentase \\
\hline 1 & $65-70$ & 3 & $9.99 \%$ \\
\hline 2 & $71-76$ & 6 & $19.98 \%$ \\
\hline 3 & $77-82$ & 9 & $29.97 \%$ \\
\hline 4 & $83-88$ & 10 & $33.3 \%$ \\
\hline 5 & $89-95$ & 2 & $6.66 \%$ \\
\hline \multicolumn{2}{c}{ Jumlah } & 30 & $100 \%$
\end{tabular}

Berdasarkan data diatas dapat diketahui nilai Prost Test siswa yaitu 3 responden memperoleh skor sekitar 65-70 sebesar 9.99\%, 6 responden memperoleh skor sekitar 71-76 sebesar 19.98\%, 9 responden memperoleh skor sekitar 77-82 sebesar 29.97\%, 10 responden memperoleh skor sekitar 83-88 sebesar $33.3 \%, \quad 2$ responden memperoleh skor sekitar 89-95 sebesar $6.66 \%$.

\section{Gambar 1. Diagram Nilai rata-rata Pre Test dan Post Test Kelas V}

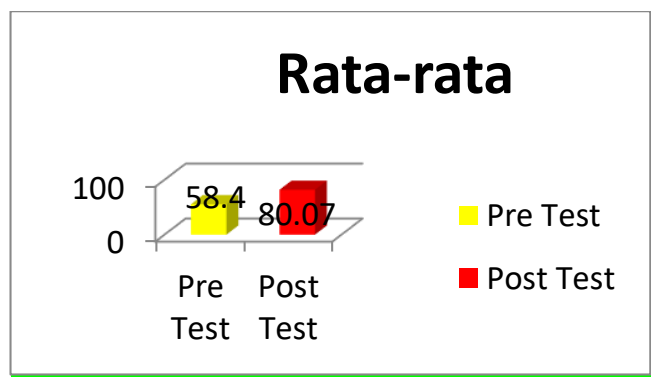

Hasil pengolahan data angket kelas V dalam bentuk distribusi frekuensi dilihat di bawah ini:

Tabel 3. Distribusi Frekuensi hasil Angket

\begin{tabular}{c|c|c|c}
\hline No & Nilai & Frekuensi & Presentase \\
\hline $\mathbf{1}$ & $50-51$ & 7 & $23,33 \%$ \\
\hline $\mathbf{2}$ & $52-53$ & 6 & $19,99 \%$ \\
\hline $\mathbf{3}$ & $54-55$ & 9 & $29,99 \%$ \\
\hline $\mathbf{4}$ & $56-57$ & 6 & $19,99 \%$ \\
\hline $\mathbf{5}$ & $58-60$ & 2 & $6,66 \%$ \\
\hline \multicolumn{2}{c}{ Jumlah } & 30 & $100 \%$ \\
\hline
\end{tabular}

Berdasarkan data di atas dapat diketahui besar presentase hasil angket siswa yaitu: 7 responden memperoleh skor disekitar 50-51 sebesar 23,33\%, 6 responden memperoleh skor disekitar 52-53 sebesar 19,99\%, 9 responden memperoleh skor sekitar 54-55 sebesar 29,99\%, 6 responden memperoleh skor sekitar 56-57 sebesar 19,99\%, 2 responden memperoleh skor sekitar 58-60 sebesar $6,66 \%$.

\section{Pembahasan}

Hasil perhitungan normalitas menggunakan uji KolmogorovSmirnov berbantuan Microsoft Excel terdapat pada tabel 4.8

Tabel 4. Nilai Korelasi Pengaruh Model Pembelajaran Quantum Teaching terhadap Hasil Belajar Siswa

\begin{tabular}{l|l|l|l|l|l}
\hline $\mathbf{N o}$ & $\mathbf{X}$ & $\mathbf{Y}$ & $\mathbf{X 2}$ & $\mathbf{Y 2}$ & $\mathbf{X Y}$ \\
\hline 1 & 54 & 80 & 2916 & 6400 & 4320 \\
\hline 2 & 56 & 84 & 3136 & 7056 & 4704 \\
\hline 3 & 55 & 90 & 3025 & 8100 & 4950 \\
\hline 4 & 50 & 72 & 2500 & 5184 & 3600 \\
\hline 5 & 53 & 67 & 2809 & 4489 & 3551 \\
\hline 6 & 58 & 88 & 3364 & 7744 & 5104 \\
\hline 7 & 55 & 72 & 3025 & 5184 & 3960 \\
\hline 8 & 53 & 80 & 2809 & 6400 & 4240 \\
\hline 9 & 54 & 84 & 2916 & 7056 & 4536 \\
\hline 10 & 56 & 72 & 3136 & 5184 & 4032 \\
\hline 11 & 55 & 84 & 3025 & 7056 & 4620 \\
\hline 12 & 50 & 88 & 2500 & 7744 & 4400 \\
\hline 13 & 50 & 77 & 2500 & 5929 & 3850 \\
\hline 14 & 55 & 72 & 3025 & 5184 & 3960 \\
\hline 15 & 54 & 65 & 2916 & 4225 & 3510 \\
\hline 16 & 57 & 75 & 3249 & 5625 & 4275 \\
\hline 17 & 57 & 80 & 3249 & 6400 & 4560 \\
\hline 18 & 58 & 82 & 3364 & 6724 & 4756 \\
\hline 19 & 52 & 85 & 2704 & 7225 & 4420 \\
\hline 20 & 50 & 82 & 2500 & 6724 & 4100 \\
\hline 21 & 52 & 69 & 2704 & 4761 & 3588 \\
\hline 22 & 52 & 88 & 2704 & 7744 & 4576 \\
\hline 23 & 53 & 82 & 2809 & 6724 & 4346 \\
\hline 24 & 50 & 90 & 2500 & 8100 & 4500 \\
\hline 25 & 50 & 82 & 2500 & 6724 & 4100 \\
\hline 26 & 56 & 82 & 3136 & 6724 & 4592 \\
\hline 27 & 56 & 85 & 3136 & 7225 & 4760 \\
\hline 28 & 55 & 75 & 3025 & 5625 & 4125 \\
\hline 29 & 55 & 85 & 3025 & 7225 & 4675 \\
\hline 30 & 50 & 85 & 2500 & 7225 & 4250 \\
\hline & $\mathbf{1 6 1 1}$ & $\mathbf{2 4 0 2}$ & $\mathbf{8 6 7 0 7}$ & $\mathbf{1 9 3 7 1 0}$ & $\mathbf{1 2 8 9 6 0}$ \\
\hline & & & & &
\end{tabular}


Untuk melihat pengaruh dari kedua variabel dapat dilakukan dengan membandingkan antara $r_{\text {hitung }}$ dengan $r_{\text {tabel }}$. Dari perhitungan secara manual di atas dapat dilihat nilai koefisien korelasi sebesar 0,705. Sedangkan uji koefisien korelasi berbantuan SPSS ver 22 pada tabel 4.10 dibawah ini:

Tabel 5. Uji Koefisien Korelasi Correlations

\begin{tabular}{ll|r|r}
\hline & \multicolumn{1}{|c}{$\begin{array}{c}\text { Model } \\
\text { Quantum } \\
\text { Teaching }\end{array}$} & \multicolumn{1}{c}{$\begin{array}{c}\text { Hasil } \\
\text { Belajar }\end{array}$} \\
\hline $\begin{array}{l}\text { Model Quantum } \\
\text { Teaching }\end{array}$ & Pearson & 1 & .705 \\
& Correlation & & .000 \\
& Sig. (2-tailed) & 30 & 30 \\
\hline Hasil Belajar & Pearson & .705 & 1 \\
& Correlation & .000 & \\
& Sig. (2-tailed) & 30 & 30 \\
& $\mathrm{~N}$ & &
\end{tabular}

Dari tabel di atas menunjukkan bahwa nilai koefisien korelasi sebesar 0,705. Jika $r_{\text {hitung }}>$ $r_{\text {tabel }}$ sehingga $r_{\text {hitung }}(0,705)>r_{\text {tabel }}$ $(0,361)$. Maka terdapat pengaruh yang kuat antara model pembelajaran Quantum Teaching terhadap hasil belajar siswa. Dapat disimpulkan terdapat pengaruh yang kuat antara model pembelajaran Quantum Teaching terhadap hasil belajar siswa kelas V SD Negeri 106144 Sei Mencirim sebesar 70,5\%. Dan sebanyak 29,95 \% dipengaruhi oleh faktor lain yang tidak dikaji dalam penelitian ini.
Tabel 6. Uji-t

Coefficients $^{\mathrm{a}}$

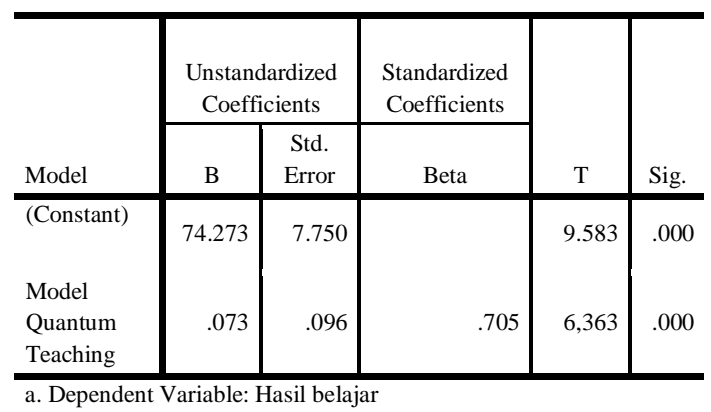

Untuk mengetahui ada atau tidaknya pengaruh dapat dilihat hasil signifikan yang diperoleh $0,000<$ 0,05 . Hasil perhitungan uji-t dari SPSS ver 22 sebesar 6,363. Untuk mendukung hasil uji-t dari SPSS ver 22, maka berikut hasil uji-t secara manual. Dapat diketahui dari nilai $t_{\text {hitung }}>t_{\text {tabel }}$ yaitu $6,363>1,697$ yang artinya ada pengaruh model pembelajaran Quantum Teaching terhadap hasil belajar siswa.

\section{SIMPULAN}

Berdasarkan pembahasan bab ini peneliti menguraikan simpulan, implikasi, keterbatasan penelitian, dan saran yang disusun berdasarkan seluruh kegiatan penilitian mengenai pengaruh model Quantum Teaching terhadap hasil belajar siswa kelas V SD Negeri 106144 Sei Mencirim Tahun Pembelajaran 2020/2021 sebagai berikut : Pada kelas V dengan menggunakan model Quantum Teaching pada materi pembelajaran tematik lingkungan sahabat kita di SD Negeri 106144 Sei Mencirim Tahun Pembelajaran 2020/2021 kelas V hasil angket siswa rata-rata Angket Test 53,7 dengan kategori sangat tinggi. Berdasarkan hasil normalitas dengan 
menggunakan Uji Liliefors (Shapiro Wilk) dengan hasil $200<0,925$ yang dapat dikatakan data berdistribusi normal. Berdasarkan pengujian koefisien korelasi dapat dilihat bahwa nilai koefisien korelasi sebesar 0,705 artinya $r_{\text {hitung }}(0,705)>r_{\text {tabel }}$ $(0,361)$. Maka terdapat pengaruh yang kuat dan terdapat pengaruh model pembelajaran SAVI Terhadap hasil belajar di kelas V SD Negeri 106144 Sei Mencirim. Berdasarkan perhitungan hasil penelitian menunjukkan bahwa terdapat pengaruh model Quantum Teaching terhadap hasil belajar siswa pada materi ajar tematik lingkungan sahabat kita di kelas V SD Negeri 106144 Sei Mencirim Tahun Pembelajaran 2020/2021 dengan $t_{\text {hitung }}>t_{\text {tabel }}$ dimana $6,363>1,697$ pada taraf signifikan $\alpha=0,05$. Dengan demikian $H_{a}$ diterima dan $H_{0}$ ditolak.

\section{DAFTAR RUJUKAN}

Badar. 2015. Mendesain model Pembelajaran. Medan: Bumi Aksara.

Fathurrohman. 2015. Model-model Pembelajaran Inovatif. Yogyakarta: AR-RUZZ Media.

Gaol, R. L., \& Simarmata, E. J. 2019. Efektivitas Bahan Ajar Tematik Sekolah Dasar Berbasis Budaya Lokal Melalui Penerapan Model Pembelajaran Contextual Teaching and Learning (CTL) Terhadap Aktivitas Belajar Siswa. Guru Kita, 3(4), 342-348.

Hamalik. 2018. Proses Belajar Mengajar. Jakarta: Bumi Aksara. Huda. 2017. Model-model Pengajaran dan Pembelajaran. Yogyakarta: Pustaka Pelajar.

Isjoni. 2018. Pembelajaran Kooperatif. Yogyakarta: PT Pustaka Pelajar.

Istarani. 2015. Model pembelajaran inovatif. Medan: Media Persada.

Juliana. 2020. Pengaruh Pendekatan Saintifik dan Aktivitas Siswa terhadap Kemampuan Menulis Deskripsi Siswa di Kelas V SDS Gracia Sustain Medan. Jurnal Tunas Bangsa, 7(2), 295-309.

Karo, T. B., Anzelina, D., Sembiring, N., \& Tanjung, D. S. 2021. Meningkatkan Hasil Belajar Siswa dengan Menggunakan Model Spider Webbed pada Pembelajaran Tematik. EDUKATIF : JURNAL ILMU PENDIDIKAN, 3(4), 2108-2117. Marta, F., Simorangkir, A., \& Tanjung, D. S. 2019. Pendekatan Multiple Intelligences Berbasis Budaya. 7(4), 302-304.

Nainggolan, M., Tanjung, D. S., \& Simarmata, E. J. 2021. Pengaruh Model Pembelajaran $S$ AVI terhadap Hasil Belajar Matematika Siswa di Sekolah Dasar. Jurnal Basicedu, 5(4), 2617-2625.

Saragih, L. M., Tanjung, D. S., \& Anzelina, D. 2021. Pengaruh Model Pembelajaran Open Ended t erhadap Hasil Belajar Siswa pada Pembelajaran Tem atik. Jurnal Basicedu, 5(4), 26442652.

Simorangkir, F. M. A., \& Tanjung, D. S. 2019. Analisis Pelaksanaan Pembelajaran Tematik dengan 
Pendekatan

Multiple

Intelligencesberbasis Budaya

Batak Angkola untuk Siswa Kelas

IV Sekolah Dasar. Jurnal

Education and Development, 7(4), 302-304.

Simorangkir, F. M. A., \& Tanjung, D.

S. 2019. Implementation of Multiple Intelligences Approach Based On Batak Angkola Culture in Learning Thematic For Class IV SD Negeri 100620 Pargarutan Julu South Tapanuli District. Budapest International Research and Critics in Linguistics and Education (BirLE) Journal, 2(4), 547-551. https://doi.org/10.33258/birle.v2 i4.538

Ngalimun. 2017. Strategi dan Model Pembelajaran. Yogyakarta: Aswaja Pressindo.

Pulungan, I. 2019. Ensiklopedi pendidikan. Medan: Media Persada.

Reardon. 2019. Quantum Teaching. Bandung: Raja Grafindo Persada. Rusman. 2019. Model-model Pembelajaran. Jakarta: Raja Grafindo Persada.

Sagala. 2018. Konsep dan Makna Pembelajaran. Bandung: Alfabeta.
Shoimin. 2019. Model Pembelajaran. Depok: AR-RUZZ Media.

Slameto. 2016. Belajar dan Faktorfaktor yang Mempengaruhi. Jakarta: RINEKA CIPTA.

Susanto. 2017. Teori Belajar dan Pembelajaran. Jakarta: Prenadamedia Group.

Syaiful. 2018. Konsep dan Makna Pembelajaran. Bandung: Alfabeta.

Tanjung, D. 2016. meningkatkan hasil belajar IPS siswa dengan menerapkan model pembelajaran kooperatif tipe time gemes tournament (TGT) di kelas $V$ SDN 200111 Padang sidempuan. IV

Tarigan, E. B., Simarmata, E. J., Abi, A. R., \& Tanjung, D. S. 2021. Peningkatan Hasil Belajar Siswa dengan Menggunakan Model Problem Based Learning pada Pembelajaran Tematik. EDUKATIF : JURNAL ILMU PENDIDIKAN, 3(4), 2294-2304.

Wasliman. 2019. Belajar dan Faktorfaktor yang mempengaruhi. Jakarta: Rineka cipta.

Wena. 2016. Hasil Belajar dan Makna Pembelajaran. Jakarta: Media. 